\title{
Land tenure considerations are key to successful mangrove restoration
}

To the Editor - Lee and colleagues ${ }^{1}$ compellingly suggest that restoring mangrove cover by using the widely practiced planting of mangroves, particularly monogeneric stands of Rhizophora (stilted mangroves), is not the solution to mangrove loss. They suggest that mangrove recovery must include protection of the remaining habitat and restoration of the degraded habitat, particularly in mangrove lands converted for shrimp aquaculture and agriculture. However, for mangrove recovery to be achieved, the drivers of inappropriate and ineffective mangrove planting programs must explicitly be considered.

Inappropriate mangrove planting programs often occur when project managers respond to inappropriate performance metrics imposed by external funding agencies, with short time frames for delivery. This process precludes both attention to the underlying drivers of mangrove deforestation, which often relate to inequality and land tenure ${ }^{2}$, and the development of participatory community restoration of degraded mangroves ${ }^{3}$. Because of their inability to resolve land-use and land-tenure issues, these ambitious, shortterm mangrove restoration projects often plant mangroves on lands that are not owned by anyone. Such lands are frequently low in the intertidal frame and are therefore unsuitable for mangrove growth, thus ultimately leading to the failure described by Lee and colleagues.

We suggest that improving mangrove restoration requires investment in a range of measures to address the underlying factors leading to mangrove deforestation and degradation. These issues are complex and time consuming to resolve, and include realignment of government policy, negotiations over land tenure, and consideration of compensation and alternate livelihoods. For example, where law enforcement is weak, and government policy supports aquaculture production and export for foreign cash earnings, those with the capital to conduct aquaculture will acquire and clear mangroves regardless of formal land use designations. Restoration of these lands would require changes in government policy; negotiation with aquaculture landholders, who typically do not live in the local community and have little incentive to restore the land; and engagement with the local community, whose members are often unwilling and unable to challenge the landholders, and may doubt that restoration will benefit them. Working with wealthy and illegal landowners may run against the mandate of many institutions that finance mangrove restoration, such as development banks, aid agencies and international foundations. However, unless innovative approaches are developed to address the land-tenure bottleneck, mangroves will continue to be planted inappropriately on uncontested land and will remain degraded.

It is equally important to address this issue from a multi-disciplinary perspective with new research into social, economic and policy factors alongside biophysical considerations ${ }^{4}$. Mangrove restoration opportunity will hinge on mediation by informed facilitators who are versed in forest conflict resolution. Heavy-handed solutions that prioritize enforcement to enable mangrove restoration-such as forceful eviction of land users-are likely to perpetuate or exacerbate conflict or result in mangrove clearing in other areas (known as leakage).

Engendering support for restoration from local communities requires time frames of 5-10 years, to build trust, confidence and willingness to participate; moreover, up to $50 \%$ of project budgets may be needed to support this process ${ }^{3}$. Mechanisms involved might include agreements to eliminate land and aquaculture taxes on restored mangrove land, assisting traditional owners without land certificates in registering land ownership, and developing and adhering to community forestry management plans for timber harvest and access to non-timber forest products, including fisheries products. Without such community engagement and agreements in place, even the most technically feasible mangrove restoration could fail because of continued exploitation. To achieve large-scale mangrove restoration, the suggestions of Lee and colleagues must be followed, but project proponents must also fund long-term projects and social interventions. The key performance indicators of restoration success should include indicators of socio-economic sustainability rather than simple measures of mangrove propagules being planted and mangrove area being created.

Catherine E. Lovelock (D) 1* and

Benjamin M. Brown²

${ }^{1}$ School of Biological Sciences, The University of Queensland, St Lucia, Queensland, Australia.

${ }^{2}$ Research Institute for the Environment and

Livelihoods, Charles Darwin University, Darwin, Australia.

*e-mail:c.lovelock@uq.edu.au

Published online: 8 July 2019

https://doi.org/10.1038/s41559-019-0942-y

References

1. Lee, S. Y., Hamilton, S., Barbier, E. B., Primavera, J. \& Lewis, R. R. Nat. Ecol. Evol. 3, 870-872 (2019).

2. Thompson, B. S. Land Use Policy 78, 503-514 (2018).

3. Brown, B., Fadillah, R., Nurdin, Y., Soulsby, I., \& Ahmad, R. S.A.P.I.EN.S http://journals.openedition.org/sapiens/1589 (2014).

4. Worthington, T. \& Spalding, M. Mangrove Restoration Potential: a Global Map Highlighting a Critical Opportunity (IUCN, 2019); https://oceanwealth.org/applications/mangrove-restoration/

Competing interests

The authors declare no competing interests. 